\title{
Relationship between Components of urinary crystallites and Formation of Calcium Oxalate Stones---An Investigation of 275 Cases of Patients with Calcium Oxalate Stones
}

\author{
Cai-Yan Tan \\ Institute of Biomineralization and Lithiasis Research \\ Jinan University \\ Guangzhou 510632 \\ Email: 919889326@qq.com \\ Jian-Ming Ouyang* \\ Institute of Biomineralization and Lithiasis Research \\ Jinan University \\ Guangzhou 510632 \\ Email: toyjm@jnu.edu.cn
}

\author{
Chong-Yu Zhang \\ Institute of Biomineralization and Lithiasis Research \\ Jinan University \\ Guangzhou 510632 \\ Email: 519460133@qq.com
}

\begin{abstract}
Purpose] This study aimed to investigate the components of urinary crystallites in $\mathbf{2 7 5}$ cases of patients with calcium oxalate (CaOx) stones compared with the components of stones. [Methods] X-ray diffraction (XRD), Fourier-transform infrared (FT-IR) spectrometer, selected area electron diffraction (SAED) and fast Fourier transformation (FFT) of high-resolution transmission electron microscopy (HRTEM) were performed. [Results] The main components of urinary crystallites in patients with $\mathrm{CaOx}$ stones were calcium oxalate monohydrate (COM), uric acid (UA), calcium oxalate dihydrate (COD) and calcium phosphate (CaP), which were similar to the components of stones (COM, COD, UA, and CaP). [Conclusions] The formation of $\mathrm{CaOx}$ stone was related to the presence of COM, UA, and CaP crystals in urine. UA and $\mathrm{CaP}$ crystals could induce the development of $\mathrm{CaOx}$ stones by heterogeneous nucleation. The formation mechanism and the influential factors of $\mathrm{CaOx}$ stones were discussed on the basis of the components of urinary crystallites.
\end{abstract}

Key words: Urine crystallite; urinary stones; calcium oxalate; XRD; TEM

\section{INTRODUCTION}

Urolithiasis is a frequently occurring urologic disease worldwide $[1,2]$. For example, the overall probabilities of forming stones in Saudi Arabia, North America, and Europe are $20 \%, 13 \%$, and $5 \%$ to $9 \%$, respectively [3]. Urinary stone is mainly treated by extracorporeal shock wave lithotripsy (ESWL) [4]. However, stone recurrence and regrowth rates after ESWL are high, particularly reported as $40 \%$ in 3 years, $74 \%$ in 10 years, and $98 \%$ in 25 years after therapy [3].

Urinary stones can be classified as acidic (e.g., UA and cystine), alkaline (e.g., MAP), and neutral (e.g., CaOx) stones based on their chemical properties. Urinary stones with different components vary not only in their physical properties (such as hardness, morphology, and solubility) but also in their chemical properties (phase component, acid-base property, and element). Therefore, the curative effects of drug and extracorporeal shock wave lithotripsy (ESWL) are quite different. However, the same methods and the same drugs are currently used in clinical practice to treat patients with stones, and the specific compositions of the stones are not distinguished. Hence, different curative effects and low treatment rates are obtained. If the specific type of urinary stones can be determined before stones are removed and treatment, a personalized treatment can be used, thereby preventin the recurrence of urinary stones.

There exists a close relation between urinary crystallites and kidney stones [5-7]. The disappearance of a specific type of urinary crystallites (e.g. cystine, struvite) in human urine may reduce calculi recurrence trend of corresponding crystal types (e.g. cystine stone, struvite calculus), whereas their constant occurrence or reoccurrence generally indicates the calculi activity or relapse, respectively. Therefore, it is likely to shed light on clinically suiting remedy to the case and personalized treatments by analyzing the urine crystalline components.

Based on the discussed above, the components of urinary crystallites in 275 cases of patients with calcium oxalate $(\mathrm{CaOx})$ stones were investigated and compared with the components of stones.

\section{MATERIALS AND METHODS}

\section{A. Reagents and instruments}

Absolute ethanol was of analytical purity. Glass vessels were cleaned with distilled water.

$\mathrm{X}$-ray diffraction (XRD) results were recorded using a D/max 2400 X-ray diffractometer (Rigaku, Tokyo, Japan) with Ni-filtered $\mathrm{Cu} \mathrm{Ka}$ radiation $\left(\mathrm{k}=1.54 \mathrm{~A}^{\circ}\right)$ at a 
scanning rate of $2^{\circ} \mathrm{min}^{-1}(40 \mathrm{kV}, 30 \mathrm{~mA})$. The divergence and scattering slit was $1^{\circ}$ for the range of $5^{\circ}<2 \theta<60^{\circ}$. A Nicolet 6700 Fourier-transform infrared (FT-IR) spectrometer (Nicolet Company, USA) was also used. TEM was conducted on a HRTEM (JOEL 2100F) with a maximum acceleration voltage of $200 \mathrm{kV}$ and lattice resolution of 0.19 . To determine the component of urinary crystallites, we performed HRTEM, fast Fourier transformation (FFT), and selected area electron diffraction (SAED) of HRTEM. FFT analysis in the Digital Micrograph software was also conducted to obtain the patterns.

\section{B. Collection and component detection of stones}

275 cases of calcium oxalate stones were collected from patients with calculi after surgery. The age of patients ranged from 20 years to 80 years with a mean age of 46.3 years. Urinary stones were then disinfected with $75 \%$ alcohol to kill bacteria, cleaned with distilled water, and placed in a dust-free incubator at $45{ }^{\circ} \mathrm{C}$ to dry. Afterward, these urinary stones were ground to powder by using an agate mortar for XRD and FT-IR characterization.

\section{Collection, treatment, and XRD and FT-IR detection of urinary crystallites}

Fasting morning urines samples were collected from patients who were instructed to fast before sampling was performed. $\mathrm{pH}$ was detected and $2 \% \mathrm{NaN}_{3}$ solution (10 $\mathrm{mL} / \mathrm{L}$ urine sample) was added to the urine samples as antiseptic. Approximately $30 \mathrm{~mL}$ of urine was then centrifuged at $4000 \mathrm{r} / \mathrm{m}$ for $15 \mathrm{~min}$, and the supernatant was removed. The residual was washed and allowed to stand for $3 \mathrm{~min}$; the supernatant was then removed. This process was repeated twice. The residual was placed on clean glass slides by using a dropper. The slides were dried in a vacuum desiccator for further XRD and FT-IR characterization.

\section{HRTEM detection of urinary crystallites}

In addition to XRD and FT-IR characterization, HRTEM, SEAD and FFT were performed to investigate the components and elements found in urinary crystallites. The urine sample was initially subjected to ultrasound treatment for $5 \mathrm{~min}$. Approximately $5 \mu \mathrm{L}$ of urine was submerged in a copper mesh by using a microsyringe; urine was preliminarily dried using an absorbent paper from the back of the mesh to remove the water content of urine. After treatment was performed, most of the soluble salts (such as $\mathrm{NaCl}$ and urea) in urine were removed by the filter paper. The mesh was then stored in a desiccator for $2 \mathrm{~d}$ before HRTEM analyses were performed.

\section{RESULTS AND DISCUSSION}

\section{A. Component analysis of stones}

The components of 452 cases of urinary stones were analyzed by XRD and FT-IR; among these cases, 275 showed $\mathrm{CaOx}$ stones (pure $\mathrm{CaOx}$ stones and mixed stones with $\mathrm{CaOx}$ as the main component).

Fig. 1 showed the XRD spectra of the stones from 12 cases of representative patients with $\mathrm{CaOx}$ stones. We detected the peaks at $\mathrm{d}=5.93,3.65,2.97,2.49,2.35,2.26$, 2.07 and $1.98 \AA$, which were assigned to (101), (020),
( $\overline{2} 02),(112),(130),(202),(321)$ and $(\overline{3} 03)$ planes of calcium oxalate monohydrate (COM) crystal [8], respectively. We also detected the peaks at $\mathrm{d}=6.55,3.86$, $3.18,3.08$, and $1.79 \AA$, which were assigned to (200), ( 111$),(121),(221)$, and (223) planes of uric acid (UA), respectively. We detected the peaks at $\mathrm{d}=2.26,2.071 .89$, 1.74 and $1.69 \AA$, which were assigned to (1016), (0018), (238), (330), and (508) planes of calcium phosphate (CaP), respectively, and the peaks at $\mathrm{d}=3.44,2.78,1.94$ and 1.84 $\AA$, which were assigned to (002), (112), (222) and (213) planes of hydroxyapatite (HAP), respectively. That is, the main components of $\mathrm{CaOx}$ stones were found to be $\mathrm{COM}$, $\mathrm{UA}$ and $\mathrm{CaP}$.
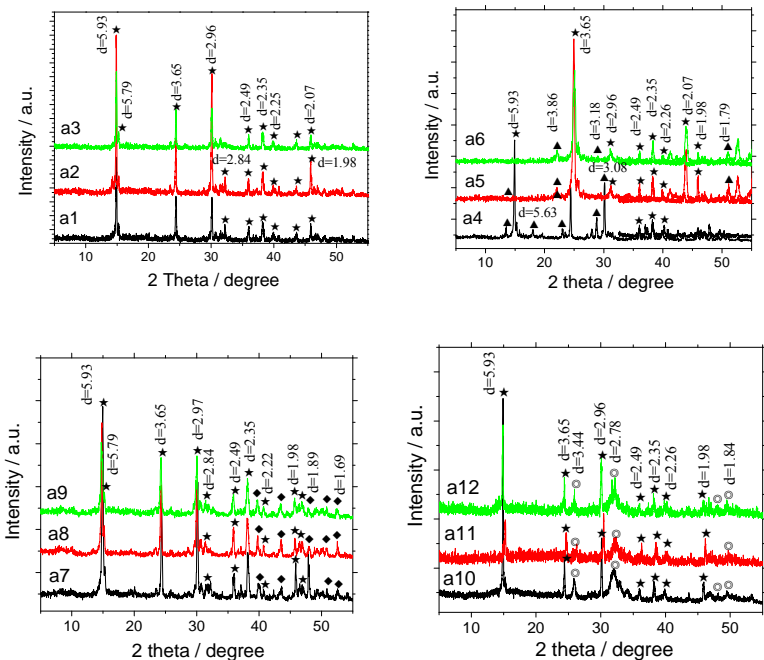

Figure 1. XRD patterns of representative 12 cases of $\mathrm{CaOx}$ stones. ( $\star$ : COM; $\boldsymbol{\Delta}$ : uric acid; $\diamond: \beta-\mathrm{Ca}_{3}\left(\mathrm{PO}_{4}\right)_{2} ;$ (O) : hydroxyapatite)

Fig. 2 showed the FT-IR spectra of representative 12 cases of $\mathrm{CaOx}$ stones. The peaks of coordinated water were located at $3488 \mathrm{~cm}^{-1}$ to $3219 \mathrm{~cm}^{-1}$. These broad peaks were attributed to the symmetrical stretching vibration and asymmetrical stretching vibration of $\mathrm{OH}$ - of coordinated water molecules. The main antisymmetric carbonyl stretching band $\left(v_{\mathrm{as}}\left(\mathrm{COO}^{-}\right)\right)$specific to the oxalate family occurs at $1622 \mathrm{~cm}^{-1}$ for COM. The secondary carbonyl stretching bands, the metal-carboxylate stretch, $v_{\mathrm{s}}\left(\mathrm{COO}^{-}\right)$ is located at $1317 \mathrm{~cm}^{-1}$ for COM. The absorption peaks at 2924,1383 , and $1023 \mathrm{~cm}^{-1}$ were assigned to CaP. The peaks at $3017,1673,1123$, and $993 \mathrm{~cm}^{-1}$ were assigned to UA. FT-IR detection results were consistent with those obtained from XRD.

\section{B. Component analysis of urinary crystallites in patients of $\mathrm{CaOx}$ stones}

XRD and FT-IR were performed to investigate the components of urinary crystallites of the 275 cases of $\mathrm{CaOx}$ stone formers above. Some of the samples were further investigated by HRTEM and FFT to accurately study their components. The results are listed as follows.

Urinary crystallites were detected in 171 cases of patients among the 275 cases of patients with $\mathrm{CaOx}$ stone as the main component (Fig. 3); these crystallites mainly contained COM, UA, and COD and a small amount of $\mathrm{CaP}$ and calcium hydrophosphate (Table 1). 

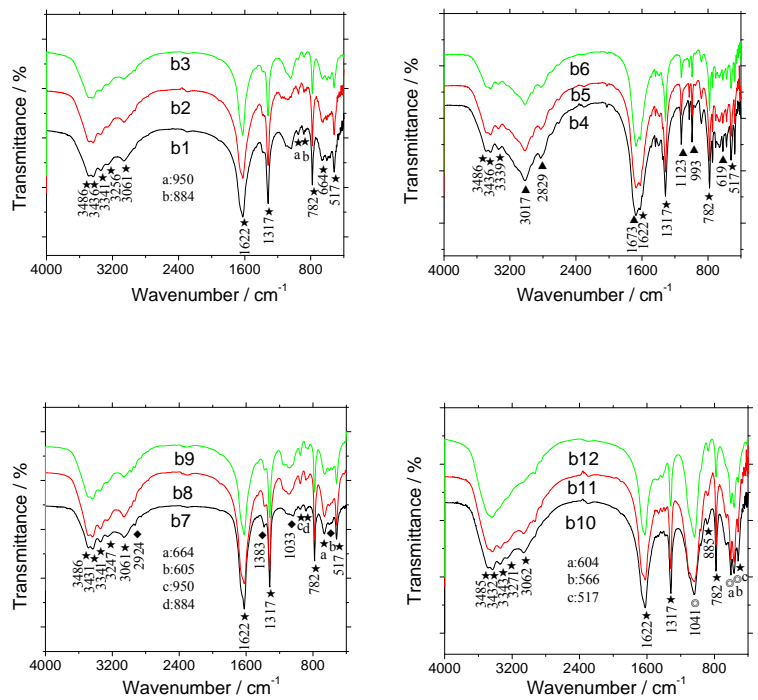

Figure 2. FT-IR spectra of representative 12 cases of $\mathrm{CaOx}$ stones.

TABLE I. COMPONENTS OF URINARY CRYSTALLITES IN 275 CASES OF CAOX STONE PATIENTS

$\begin{array}{llll}\text { No. } & \begin{array}{l}\text { Components of } \\ \text { Urinary crystallites }\end{array} & \text { Number } & \text { Percentage } \\ & \text { COM+UA *;** } & \text { / }\end{array}$

\section{1) XRD analysis of urinary crystallites}

Fig. 4 showed the XRD spectra of urinary crystallites from 8 cases of the representative patients with $\mathrm{CaOx}$ stones above. We detected the peaks at $\mathrm{d}=5.93,3.65$, $2.97,2.49,2.36,1.98$ and $1.73 \AA$, which were assigned to

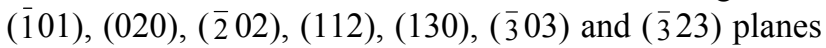
of COM, respectively [8]. We also detected the peaks at $\mathrm{d}$ $=4.91,3.93,3.16$ and $2.93 \AA$, which were assigned to (210), ( $\overline{2} 11),(\overline{1} 21)$ and $(\overline{2} 21)$ planes of uric acid (UA) crystal, respectively, and $\mathrm{d}=8.17,2.60$ and $2.20 \AA$, which were assigned to (1012), (220) and (404) plane of CaP.
That is, the main components of $\mathrm{CaOx}$ stones were found to be $\mathrm{COM}$, UA and $\mathrm{CaP}$, and urinary crystallites were also composed of COM, UA and $\mathrm{CaP}$.

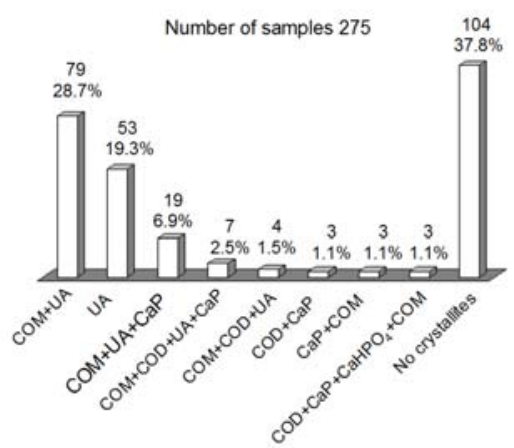

Figure 3. Components of urinary crystallites in 275 cases of $\mathrm{CaOx}$ stone patients
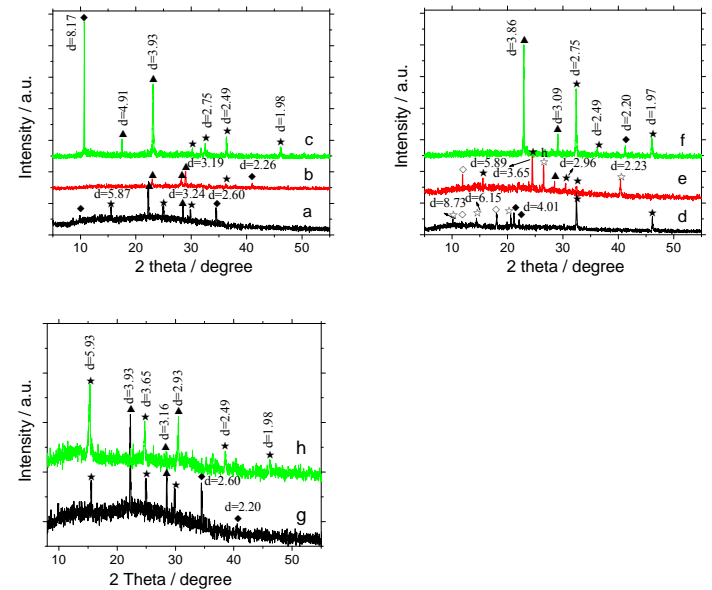

Figure 4. XRD spectra of urinary crystallites in 8 representative $\mathrm{CaOx}$ stone patients. Symbols: $\star$ : COM; 色: COD; $\boldsymbol{\Delta}$ : uric acid; $\diamond$ : ammonium urate; $\bullet: \mathrm{Ca}_{3}\left(\mathrm{PO}_{4}\right)_{2}$.

2) HRTEM analysis of urinary crystallites

Fig. 5 showed the images obtained from HRTEM and FFT of the urinary crystallites.

The sub-maximal diffraction peaks of COM $(d=5.76$, 2.96, 2.75, 2.49, 2.35 and $2.07 \AA$ ) were detected and was assigned to the ( $\overline{1} 10),(\overline{2} 02),(420),(112),(130)$ and (321) plane of COM crystal, respectively [8].That is, the main crystal plane of COM were detected in these HRTEM images.

\section{3) SAED analysis of urinary nanocrystallites}

Selected area electron diffraction (SAED) was carried out to further characterize the components of urinary nanocrystallites. Fig. 6 showed the images of (SAED of the urinary crystallites. We simultaneously detected the presence of COM, UA and CaP. In SAED pattern, we detected an interplanar spacing of $\mathrm{d}=3.08 \AA$, which was assigned to the strongest plane (121) of UA. We also detected an interplanar spacings of $d=2.60$ and $1.41 \AA$, which were assigned to the (220) and (1514) planes of $\beta-\mathrm{CaP}$, respectively. Interplanar spacings of $\mathrm{d}=$ $2.49,1.98$ and $1.72 \AA$, which were assigned to (112), ( $\overline{3} 23)$, and ( $\overline{3} 03)$ planes of COM crystal [8], respectively. 


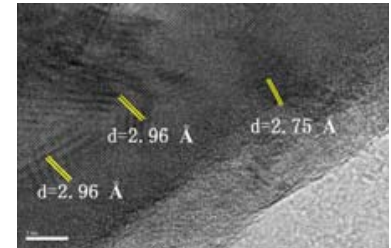

(a)

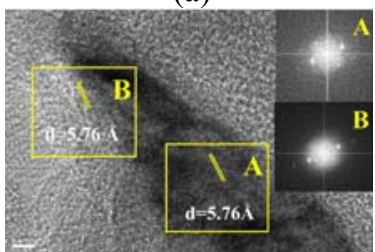

(c)

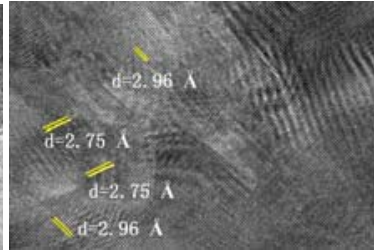

(b)

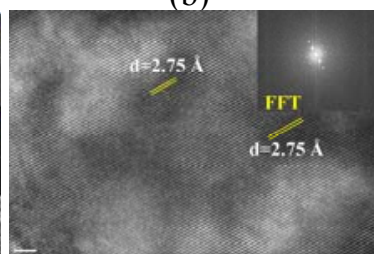

(d)

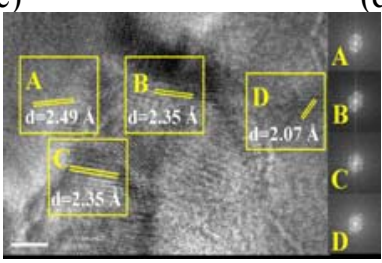

(e)

Figure 5. FFT images of HRTEM of urinary crystallites in $\mathrm{CaOx}$ stone patients.

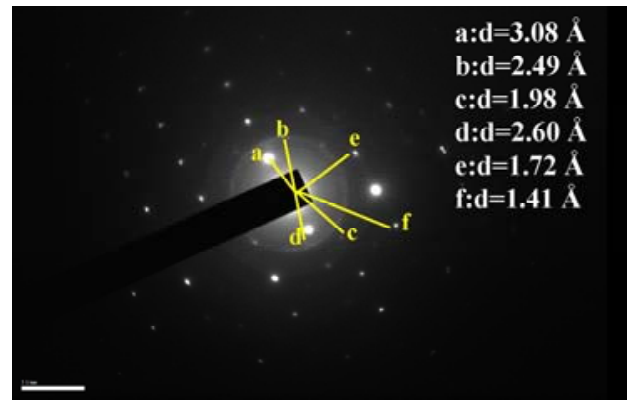

Figure 6. SAED images in different areas of urinary crystallites in patients with $\mathrm{CaOx}$ stones.

\section{DISCUSSION}

XRD, FT-IR, HRTEM, and FFT were performed to investigate the components of urinary crystallites. The results showed that the main components of urinary crystallites in patients with $\mathrm{CaOx}$ stones were UA, COM, and $\mathrm{CaP}$ (Table 1), which are similar to the components of stones (COM, COD, and small amounts of UA, $\mathrm{CaP}$, and HAP) (Fig. 1). The results also indicated that the components of urinary crystallites highly indicated the activities of stone-related diseases.

$\mathrm{CaOx}$ is the most common component of urinary stones and often accompanied by other components. This result is attributed to $\mathrm{CaOx}$ crystals that can be formed regardless of urine $\mathrm{pH}$. In acidic urine, $\mathrm{CaOx}$ usually forms stones accompanied by uric acid; in alkaline urine, $\mathrm{CaOx}$ usually forms stones accompanied by $\mathrm{HAP}, \mathrm{CaP}$, and MAP [9].

In a previous study [10], the components of $\mathrm{CaOx}$ stone in its interior region are $\mathrm{CaOx}$ and $\mathrm{CaP}$; in the surrounding region, $\mathrm{CaOx}$ stone contains $\mathrm{CaOx}$, indicating that $\mathrm{CaP}$ crystals are nidus to induce $\mathrm{CaOx}$ stone formation. In urine with $\mathrm{pH}>6$, all kinds of crystallites, such as $\mathrm{CaP}$, ACP [11], HAP [12], and carbonate apatite [13], can be formed. These crystallites can function as nidus to induce the formation of $\mathrm{CaOx}$ stone and then produce mixed stones accompanied by phosphate [14].

The formation of $\mathrm{CaOx}$ stone is often related to hyperuricosuria. In urine with $\mathrm{pH}<5.5$, the solubility of UA significantly decreases and the precipitated UA crystals can function in heterogeneous nucleation to induce the formation of $\mathrm{CaOx}$ stone; as a result, $\mathrm{COM} / \mathrm{UA}$ stone is produced [15].

It could be seen from Fig. 4 that $\mathrm{UA}$ and $\mathrm{CaP}$ were detected. These results provided evidence that UA and calcium phosphate nanocrystallites act as nidus to induce COM development/growth, leading to stone formation.

It was reported that the presence of UA crystals could induce the development of COM through heterogeneous nucleation [16]. UA can serve as a nidus to induce the generation, precipitation, and aggregation of $\mathrm{CaOx}$ crystals [17]. In addition, UA crystals, which are better than mucoproteins (a glycoprotein) and cell debris as a nucleating agent, can induce the development of COM as a heterogeneous nucleating agent [18]. Therefore, $\mathrm{CaOx}$ stone formation is closely related with hyperuricosuria [19].

On the other hand, various kinds of phosphates are present in urine, such as $\mathrm{CaP}$ [20], amorphous calcium phosphate (ACP) [21], hydroxyapatite [22], carbapatite, and so on. All of them can act as nidus to induce the development of COM calculi.

\section{CONCLUSION}

XRD, FT-IR, and HRTEM were performed to study the components of urinary crystallites in 275 cases of patients with $\mathrm{CaOx}$ stones. The main components of urinary crystallites in patients with $\mathrm{CaOx}$ stones were calcium oxalate monohydrate (COM), uric acid (UA), calcium oxalate dihydrate (COD) and calcium phosphate $(\mathrm{CaP})$, which were similar to the components of stones (COM, COD, UA, and CaP). The results showed that the formation of the $\mathrm{CaOx}$ stones was closely related to the components of urinary crystallites.

\section{ACKNOWLEDGEMENTS}

This research work was granted by the Natural Science Foundation of China (81170649).

\section{REFERENCES}

[1] S. Farmanesh, S. Ramamoorthy, J. Chung, J. R. Asplin, P. Karande, J. D. Rimer. "Specificity of growth inhibitors and their cooperative effects in calcium oxalate monohydrate crystallization," J. Amer. Chem. Soc., 2014, 136: 367-376.

[2] W. Green, H. Ratan. "Molecular mechanisms of urolithiasis," Urology, 2013, 81(4): 701-704.

[3] A. Ramello, C. Vitale, M. Marangella. "Epidemiology of nephrolithiasis," J. Nephrol., 2000, 13: 45-50.

[4] Y. Q. Xue, D. L. He, X. F. Chen, X. Li, J. Zeng, X. Y. Wang. "Shock wave induced kidney injury promotes calcium oxalate deposition," J. Urol., 2009, 182(2): 762-765.

[5] S. Verdesca, G. B. Fogazzi, G. Garigali, P. Messa, M. Daudon. "Crystalluria: prevalence, different types of crystals and the role of infrared spectroscopy," Clin. Chem. Lab. Med., 2011, 49(3): 515520 .

[6] X. Y. Sun, J. F. Xue, Z. Y. Xia, J. M. Ouyang. "Component analyses of urinary nanocrystallites of uric acid stone formers by combination of high-resolution transmission electron microscopy, 
fast Fourier transformation, energy dispersive X-ray spectroscopy, $\mathrm{X}$-ray diffraction and Fourier transform infrared spectroscopy," IET Nanobiotechnology, 2014, 9(6): 114-121.

[7] X. Y. Sun, J. M. Ouyang, F. X. Wang, Y. S. Xie. "Formation mechanism of magnesium ammonium phosphate stones: A component analysis of urinary nanocrystallites," Journal of Nanomaterials, 2015, e498932,

[8] M. Daudon, H. Bouzidi, D. Bazin. "Composition and morphology of phosphate stones and their relation with etiology," Urol. Res., 2010, 38: 459-467.

[9] F. Grases, P. Sanchis, B. Isern, J. Perelló, A. Costa-Bauzá. "Uric acid as inducer of calcium oxalate crystal development," Scand. J. Urol. Nephrol., 2007, 41(1): 26-31.

[10] Y. M. Fazil Marickar, P. R. Lekshmi, L. Varma, P. Koshy. "EDAX versus FT-IR in mixed stones," Urol. Res., 2009, 37(5): 271-276.

[11] T. Lee, Y. C. Lin. "Mimicking the initial development of calcium urolithiasis by screening calcium oxalate and calcium phosphate phases in various urinelike solutions, time points, and $\mathrm{pH}$ values at 37 C," Cryst. Growth Des., 2011, 11(7): 2973-2992.

[12] F. Grases, O. Soehnel, VilacMAPa, J. G. March. "Phosphates precipitating from articial urine and fine structure of phasphate renal calculi," Clin. Chim. Acta., 1996, 244: 45-67.

[13] H. C. Tiselius. "The role of calcium phosphate in the development of Randau's plaques," Urolithiasis, 2014, 41(5): 369-377.

[14] F. Grases, A. Costa-Bauza, M. Ramis, V. Montesinos, A. Conte. "Simple classification of renal calculi closely related to their micromorphology and etiology," Clin. Chim. Acta., 2002, 322: 2936.

[15] F. Grases, A. Costa-Bauza, I. Gomila. "Urinary $\mathrm{pH}$ and renal lithiasis," Urol. Res., 2012, 40(1): 41-46.

[16] J. H. Adair, L. A. G. Aylmore, J. G. Brockis, R. C. Bowyer. “An electrophoretic mobility study of uric acid with special reference to kidney stone formation,” J. Coll. Interf. Sci., 1988, 124(1):1-13.

[17] T. C. Ngo, D. G. Assimos. "Uric acid nephrolithiasis: recent progress and future directions," Rev. Urol., 2007, 9(1): 17-27.

[18] C. A. A. Ghumman, O. M. T. Carreira, A. M. C. Moutinho, A. Tolstogouzov, V. Vassilenko, O. M. N. D. Teodoro. "Identification of human calculi with time-of-flight secondary ion mass spectrometry," Rapid Commun. Mass Spectrom., 2010, 24(2): 185 190.

[19] L. Chen, Y. H. Shen, A. J. Xie, F. Z. Huang, W. Q. Zhang, S. X Liu. "Seed-mediated synthesis of unusual struvite hierarchical superstructures using bacterium," J. Cryst. Growth, 2010, 10(5): 2073-2082.

[20] H. P. Lee, D. Leong, C. T. Heng. "Characterization of kidney stones using thermogravimetric analysis with electron dispersive spectroscopy," Urol. Res., 2012, 40(3):197-204.

[21] P. Jolanta, T. Agnieszka. "Effect of curcumin against proteus mirabilis during crystallization of struvite from artificial urine," ECAM (Evid.-Based Compl. Alt. Med.), 2012, 2012: 1-7.

[22] R. Boistelle, F. Abbona, H. E. Lundager Madsen. "On the transformation of struvite into newberyite in aqueous systems," Phys Chem Minerals, 1983, 9: 216-222. 